\title{
PEDAGOGIA HISTÓRICO-CRÍTICA: ALTERNATIVA PARA A REVALORIZAÇÃO DOS CONTEÚDOS ESCOLARES
}

\author{
Jaqueline Daniela Basso \\ Luiz Bezerra Neto \\ UFSCar
}

\section{RESUMO}

Objetivamos neste trabalho debater a questão do "aprender a aprender" presente tanto nos objetivos dos Parâmetros Curriculares Nacionais - PCNs, quanto no Relatório Jacques Delors, publicado pela UNESCO e que tem colaborado para o esvaziamento dos currículos escolares, trazendo como alternativa para esta situação a Pedagogia Histórico - Crítica. Após revisão bibliográfica, podemos afirmar ser este um caminho para a revalorização dos conteúdos escolares e da escola, enquanto espaço para a apreensão dos conhecimentos historicamente construídos.

Palavras-chave: Pedagogia Histórico-crítica; Conteúdos Escolares; Revalorização dos conteúdos escolares.

\section{HISTORICAL-CRITICAL PEDAGOGY: A WAY FOR REVALUATION OF SCHOOL SUBJECTS}

\section{ABSTRACT}

This paper sets discuss the issue of "learning to learn" present both the objectives of the National Curriculum Parameters - NCPs, as the Delors Report, published by UNESCO and has contributed to the depletion of school curricula, as an alternative to bringing this situation to pedagogy History - Critical. After literature review, we can say that this is a way for the upgrading of school subjects and school, as an area for the apprehension of knowledge historically built.

Keywords: Historical-Critical Pedagogy, School Content, Revaluation of school subjects

É comum ouvirmos na televisão, lermos em jornais e revistas que a educação brasileira não vai bem, sobretudo, o Ensino Fundamental, etapa obrigatória da escolarização no país; percebemos por meio dos resultados de avaliações externas que nossa educação está muito aquém se comparada com a de outros países. Em outro trabalho tivemos a oportunidade de demonstrar que as influências e exigências de organismos internacionais como o Banco Mundial tem colaborado para a baixa qualidade da educação, que prima por uma formação mínima e aligeirada; por este motivo não abordaremos esta temática no presente trabalho, mas para compreende-lo é preciso ter clareza de que este é nosso pano de fundo. 
Que os resultados educacionais brasileiros não são os melhores já sabemos, porém, não conseguiremos superar esta situação de déficit educacional com os velhos jargões e preconceitos como: a culpa é da família, os alunos são indisciplinados ou o salário de professor não é justo; desta forma, o que temos conseguido é aumentar os problemas educacionais em busca de "culpados" ao invés de soluções e, consequentemente, muito pouco se tem feito na direção de revalorizar os conteúdos escolares e assim colaborarmos para uma melhor formação dos alunos.

Deste modo, pretendemos com este trabalho contribuir para a reflexão acerca do que tem direcionado a educação brasileira e corroborado para o esvaziamento dos currículos, mostrando, por meio da revisão bibliográfica, que a Pedagogia Histórico-Crítica é uma alternativa ao "aprender a aprender" que tem sido um dos responsáveis pelas mazelas do Ensino Fundamental brasileiro. Para tanto analisaremos os objetivos para o Ensino Fundamental contidos nos Parâmetros Curriculares Nacionais, os PCNs, e os princípios educacionais contidos no Relatório Jacques Delors, aceito amplamente no contexto internacional.

Newton Duarte tem se dedicado ao estudo do construtivismo, suas faces e interfaces com outros modismos pedagógicos, e aponta a pedagogia das competências, o Construtivismo, a Escola Nova e os estudos da linha "professor reflexivo", entre outros, como as chamadas pedagogias do "aprender a aprender", que no caso da pedagogia das competências, por exemplo, se traduz no aprender fazendo (DUARTE, 2001, p. 35-36).

Duarte (2001, p. 36) nos mostra que na perspectiva do construtivista espanhol César Coll,

Aprender sozinho contribuiria para o aumento da autonomia do indivíduo, enquanto aprender como resultado de um processo de transmissão por outra pessoa seria algo que não produziria a autonomia e, ao contrário, muitas vezes até seria um obstáculo para a mesma.

Duarte completa afirmando que concorda ser papel da escola desenvolver a autonomia intelectual e a iniciativa na busca por novos conhecimentos, entretanto, as pedagogias do "aprender a aprender" valorizam mais o aprender sozinho do que aquilo que é aprendido por meio da transmissão de conhecimentos (DUARTE, 2001, p. 36), acreditamos ser este o ponto mais preocupante, visto que estas pedagogias dão margem ao abandono dos conteúdos socialmente construídos pela humanidade.

Além desta questão, o autor nos alerta que as pedagogias do "aprender a aprender" priorizam a aquisição do método científico em detrimento à apreensão daquilo que a ciência já descobriu (DUARTE, 2001, p. 36- 37). Ou seja, há uma supervalorização do método e secundarização dos conteúdos, e os reflexos disto tudo são vistos e sentidos na educação brasileira e mundial, uma vez que estão presentes em documentos que norteiam as políticas educacionais.

Para compreendermos esta situação no Brasil, nos dedicaremos ao Ensino Fundamental dada a natureza deste trabalho e ao fato de ser a etapa obrigatória da educação brasileira, que compreende a escolarização entre os seis aos catorze anos de idade, dividida em dois ciclos, do primeiro ao quinto ano (primeiro ciclo), e do sexto ao nono ano (segundo ciclo). Lembrando que a Lei de Diretrizes e Bases da Educação Nacional de 1996 previa esta etapa com oito anos, sendo os dois ciclos compostos por quatro anos cada, mas, foi modificada em 2006 pela Lei 11.274, que ampliou sua duração para nove anos. 
Assim, analisaremos os objetivos contidos no volume introdutório dos Parâmetros Curriculares Nacionais, que daqui em diante denominaremos como são popularmente conhecidos, PCNs. Publicados um ano após a promulgação da LDB, ou seja, em 1997,

os Parâmetros Curriculares Nacionais constituem um referencial de qualidade para a educação no Ensino Fundamental em todo o País. Sua função é orientar e garantir a coerência dos investimentos no sistema educacional, socializando discussões, pesquisas e recomendações, subsidiando a participação de técnicos e professores brasileiros, principalmente daqueles que se encontram mais isolados, com menor contato com a produção pedagógica atual (BRASIL, 1997, p. 13).

Fica-nos claro que o objetivo principal dos PCNs é a normatização da educação brasileira, visando garantir a equidade na distribuição de recursos e acesso às discussões e conhecimentos pedagógicos, salta-nos a questão da qualidade que aparece na legislação educacional brasileira, porém, não é conceituada, tampouco mensurada.

Em seu volume introdutório, os PCNs são definidos como um documento de natureza aberta e flexível, que permite que as decisões quanto ao currículo sejam tomadas em nível regional e local, não aparecendo como um modelo homogêneo e impositivo, desta forma respeitaria a autonomia dos Estados e Municípios, bem como a diversidade do país e a autonomia dos professores e equipes pedagógicas (BRASIL, 1997, p. 13).

Percebemos o alinhamento com a política de descentralização da educação presente na LDB, que transfere recursos e responsabilidades da União para os Estados e Municípios e impactam diretamente na qualidade da educação ofertada, vejamos o que o documento nos diz:

[...] se estes Parâmetros Curriculares Nacionais podem funcionar como elemento catalisador de ações na busca de uma melhoria da qualidade da educação brasileira, de modo algum pretendem resolver todos os problemas que afetam a qualidade do ensino e da aprendizagem no País. A busca da qualidade impõe a necessidade de investimentos em diferentes frentes, como a formação inicial e continuada de professores, uma política de salários dignos, um plano de carreira, a qualidade do livro didático, de recursos televisivos e multimídia, a disponibilidade de materiais didáticos. Mas esta qualificação almejada implica colocar também, no centro do debate, as atividades escolares de ensino e aprendizagem e a questão curricular como de inegável importância para a política educacional da nação brasileira (BRASIL, 1997, p. 13).

Fica evidente que a preocupação com a qualidade passa pela formação e valorização docente, materiais e recursos pedagógicos, o currículo e o processo de ensino e aprendizagem em si, porém, o acesso aos conteúdos historicamente construídos não é mencionado.

Situação que resulta daquilo que os PCNs denominam de "Tradição Pedagógica Brasileira", se é que podemos falar em tradição, visto que, no próprio documento afirma-se que a educação brasileira é marcada pela mistura de tendências pedagógicas, ou seja, pelo ecletismo teórico-metodológico. Deste modo, são identificadas quatro grandes correntes pedagógicas no Brasil: a tradicional (centrada no professor, na vigilância e no ensino da matéria); a renovada ou Escola Nova (valoriza o indivíduo como ser livre, ativo e social); a Tecnicista (prioriza a tecnologia, professor passa a ser um especialista) e aquelas marcadas 
por preocupações sociais e políticas (BRASIL, 1997, p. 30-31) (chamadas por Dermeval Saviani de teorias críticas) onde se situa a Pedagogia Histórico-Crítica que discutiremos mais adiante.

Deste modo, fica-nos claro que os próprios documentos que norteiam o Ensino Fundamental assumem a adesão às pedagogias do aprender a aprender, que tiraram o foco do ensino dos conteúdos e o passaram para o próprio aluno ou o método de aquisição dos conhecimentos nos diferentes momentos e, por fim, a mistura de um pouco de cada um destes métodos que resultam na falta de direcionamento educacional no Ensino Fundamental.

Duarte (2001, p. 37) atenta para o fato de que a educação tem sido voltada para preparar os indivíduos para acompanhar o acelerado processo de transformação social, desta forma, os conhecimentos vão sendo superados em grande velocidade e o indivíduo que não estiver preparado para se renovar constantemente estará fadado ao fracasso no mercado de trabalho, cada vez mais concorrencial. "O 'aprender a aprender' aparece assim na sua forma mais crua, mostrando seu verdadeiro núcleo fundamental: trata-se de um lema que sintetiza uma concepção educacional voltada para a formação da capacidade adaptativa dos indivíduos" (DUARTE, 2001, p.38).

Vejamos de que modo este lema está presente no Ensino Fundamental brasileiro, os objetivos dos PCNs estão centrados nas capacidades a serem desenvolvidas pelos alunos, capacidades de ordem cognitiva, física, afetiva, de relação interpessoal e inserção social, ética e estética, em busca de uma formação ampla. $\mathrm{O}$ mesmo documento afirma que a garantia do desenvolvimento dessas capacidades necessita da disponibilidade para a aprendizagem de modo geral, e esta depende da história escolar do aluno que determinará sua motivação para o processo educacional, além de conteúdos que tenham sentido e sejam funcionais (BRASIL, 1997, p. 47- 48).

Neste processo caberia ao professor apresentar os conteúdos e atividades de modo que os alunos compreendam por que e para que estão aprendendo e assim desenvolvam expectativas positivas em relação à aprendizagem e se motivem para o trabalho escolar, além de ter claro que nem todos os indivíduos tem os mesmos interesses ou habilidades, desta forma, caberia ao professor reconhecer as diferenças individuais (BRASIL, p. 4748).

Deste modo os Parâmetros Curriculares Nacionais transferem aos alunos a responsabilidade por sua aprendizagem visto que, para desenvolver as capacidades almejadas deve haver uma disponibilidade pré-existente, fruto de um sucesso escolar e da motivação, pela qual o professor é responsabilizado ao significar os conteúdos e atividades que devem ser úteis e funcionais, ou seja, devem atender às necessidades imediatas dos indivíduos.

Entretanto, ao falar dos fundamentos psicológicos da Pedagogia Histórico-Crítica, Lígia Márcia Martins nos alerta que as condições objetivas nas sociedades de classes, como a brasileira, são desiguais, portanto oferecem condições desiguais de humanização (MARTINS, 2013, p. 131). O que significa dizer que o aluno não pode ser culpado por seu sucesso ou fracasso escolar, visto que, as aprendizagens dependem de uma série de fatores como as condições de vida e as oportunidades de escolarização.

Nesta concepção, cabe à educação escolar permitir a apropriação dos conhecimentos historicamente construídos, que enriquecerão o universo de significações dos indivíduos, dado que, quanto mais elementos o indivíduo dispuser maior será a facilidade em perceber a realidade concreta (MARTINS, 2013, p. 131 - 132). Daí crermos 
que a Pedagogia Histórico-Crítica é uma alternativa, sólida e teoricamente embasada, para a revalorização dos conteúdos no Ensino Fundamental.

Tendo em vista o objetivo geral do Ensino Fundamental: "utilizar diferentes linguagens- verbal, matemática, gráfica, plástica, corporal- como meio para expressar e comunicar suas ideias, interpretar e usufruir das produções culturais" (BRASIL, 1997, p. 48) nos parece urgente a superação deste paradigma do "aprender a aprender" que em nada tem contribuído para que a escola cumpra seu papel na transmissão dos conteúdos universais, visto que, o próprio objetivo do Ensino Fundamental nos mostra que a comunicação, e expressão por meio das diferentes linguagens seria suficiente para que o indivíduo faça proveito daquilo que a humanidade produz, vemos aqui uma total ausência de criticidade e compreensão da realidade concreta.

Entretanto, este não é um problema apenas da educação brasileira, ele se faz presente no mundo todo por meio da aceitação de diretrizes como o relatório da comissão internacional da UNESCO, "Educação: um tesouro a descobrir" conhecido como relatório Jacques Delors (presidente da comissão), publicado em 1998. O relatório foi amplamente aceito, e em seu quarto capítulo apresenta os "quatro pilares da educação" que tem sido disseminados nos muitos cursos de formação docente brasileiros desde sua publicação.

De acordo com o relatório, a educação estaria alicerçada no "aprender a conhecer", "aprender a fazer", "aprender a viver juntos, aprender a viver com os outros" e "aprender a ser” (DELORS, 1998), ou seja, aparecem aqui as capacidades cognitiva, física, interpessoal e a inserção social presentes nos objetivos dos PCNs brasileiros, mesmo publicados um ano antes, a comparação destes dois documentos nos mostram o movimento educacional mundial na direção do fortalecimento do "aprender a aprender" e consequente desvalorização dos conteúdos, tidos como símbolo do autoritarismo e "atraso" da pedagogia tradicional. Assim como nos mostra o seguinte trecho do relatório:

À educação cabe fornecer, de algum modo, os mapas de um mundo complexo e constantemente agitado e, ao mesmo tempo, a bússola que permita navegar através dele. Nesta visão prospectiva, uma resposta puramente quantitativa à necessidade insaciável de educação- uma bagagem escolar cada vez mais pesada- já não é possível nem mesmo adequada. Não basta, de fato, que cada um acumule no começo da vida uma determinada quantidade de conhecimentos de que possa abastecer-se indefinidamente. É antes, necessário estar à altura de aproveitar e explorar, do começo ao fim da vida, todas as ocasiões de atualizar, aprofundar e enriquecer estes primeiros conhecimentos, e de se adaptar a um mundo em mudança (DELORS, 1998, p.89).

O excerto nos mostra claramente que no relatório os conteúdos escolares aparecem como um fardo pesado aos nossos alunos e que cabe à educação apenas direcionar o indivíduo em sua caminhada, ou seja, uma formação superficial e instrumental seria suficiente, daí a comparação com a bússola. A formação inicial rica é trocada pela flexibilidade de aprender sempre, que não supre a formação integral humana, mas a preparação para o mercado de trabalho cada vez mais exigente e flexível, assim como já nos alertou inicialmente Newton Duarte ao falar das pedagogias do "aprender a aprender".

O relatório Delors aponta que para cumprir sua missão a educação precisa se organizar em torno dos quatros pilares no decorrer de toda a vida, porém, é salientado no documento que o ensino formal se dedica prioritariamente ao aprender a conhecer, e em 
menor escala ao aprender a fazer, enquanto as outras duas aprendizagens aparecem como desdobramento aleatório e natural destas duas primeiras (DELORS, 1998, p. 89 -90).

Observemos de modo um pouco mais detalhado quais são os pressupostos de cada um dos pilares: Aprender a conhecer, não preconiza a aquisição de um conjunto de saberes codificados, mas o domínio dos instrumentos de conhecimento, considerado como meio e fim da vida humana. O indivíduo deve aprender a compreender o mundo e atuar profissionalmente, termos como curiosidade intelectual e amizade com a ciência fazem parte deste pilar (DELORS, 1998, p. 91).

Daí a necessidade de superação deste jargão pedagógico que tem sido tão caro à educação, visto que, a centra nos métodos e não nos conteúdos, assim, a educação brasileira, sobretudo a pública, tem vivido e sentido o esvaziamento curricular e empobrecimento da formação, que focada no indivíduo e suas particularidades não lhes oferece ferramentas para que possam compreender a realidade de exploração a que são submentidos.

Nesta mesma direção aparece o aprender a fazer, intrinsecamente ligado ao aprender a conhecer e, diretamente atrelado à atuação profissional, trata-se de ensinar os alunos a colocar em prática os seus conhecimentos e também de adaptar a educação à sua ocupação laboral, tão inserta. Entretanto, o relatório nos alerta que não se pode confundir esta formação com a mera instrumentalização para o trabalho industrial, como, ao diferenciar a noção de qualificação e competência, o documento nos esclarece que os postos de trabalho tem exigido maior qualificação, assim, capacidades intelectuais seriam mais importantes do que as físicas (DELORS, 1998, p. 93-94).

De modo geral percebemos a preocupação da comissão relatora em "amenizar" a forma como o aprender a fazer é percebido, porém, nos parece claro que nada mais é do que a reafirmação do papel da educação enquanto formadora de mão de obra, papel típico dela nas sociedades capitalistas, assim, buscam colocar o trabalho intelectual à frente do físico, como se, deste modo, parte da exploração fosse apagada.

Como consequência dos dois pilares anteriores surge o aprender a viver juntos, aprender a viver com os outros, apontado no relatório como um dos maiores desafios da educação, visto que o momento atual é de muita violência e a história humana sempre foi marcada por conflitos. Portanto, caberia à educação colaborar para a melhora desta situação, entretanto, tendo em vista o espírito competitivo e individualista incentivado pelo capitalismo, ela tem colaborado para a manutenção desta situação. (DELORS, 1998, p. 9698).

Por fim aparece o último pilar, aprender a ser, que está ligado ao desenvolvimento total do indivíduo: espírito; corpo; inteligência; sensibilidade; sentido estético; responsabilidade pessoal e espiritualidades, que primeiro deve se conhecer, para depois interagir com o outro e enfrentar os conflitos presentes na sociedade (DELORS, 1998, p. 99).

Observando os quatro pilares da educação, principalmente, o aprender a conhecer, mais conhecido como o "aprender a aprender" percebemos que há uma supervalorização dos meios de aquisição dos conhecimentos, da capacidade de adaptação e da individualidade, traços também presentes nos PCNs, e que se materializam em uma escolarização instrumental, esvaziada de conteúdos e que colabora ainda mais para a concorrência e individualismo.

E onde ficam os conteúdos neste contexto? Onde está tudo aquilo que os homens já descobriram até o momento? Nos livros "velhos e ultrapassados"? (que parte das escolas brasileiras tampouco possuem em qualidade e quantidade adequada ao número de alunos?). 
É a partir destas indagações que caminharemos agora na direção do contexto que engendrou as discussões acerca da Pedagogia Histórico-Crítica no Brasil, para então compreendermos sua validade enquanto alternativa para a revalorização dos conteúdos escolares, sobretudo no Ensino Fundamental.

Recordando que as chamadas pedagogias do "aprender a aprender" compreendem, de acordo com Duarte (2001, p. 35 - 36), a pedagogia das competências, o Construtivismo, a Escola Nova e os estudos da linha "professor reflexivo", entre outros, temos que ter claro a influência da Escola Nova no Brasil, defendida no Manifesto dos Pioneiros da Educação de 1932 e sentida na educação brasileira desde aquele período.

Dermeval Saviani (2008, p. 47) alerta que o ideário escolanovista se tornou senso comum para os educadores brasileiros no século $\mathrm{XX}$, fazendo com que essa fosse a forma dominante de conceber a educação, Saviani busca se opor a este posicionamento, emprestando de Lênin o termo "teoria da curvatura da vara".

Com efeito, assim como para se endireitar uma vara que se encontra torta não basta colocá-la na posição correta, mas é necessário curvá-la do lado oposto, assim, também, no embate ideológico, não basta enunciar a concepção correta para que os desvios sejam corrigidos; é necessário abalar as certezas, desautorizar o senso comum (SAVIANI, 2008, p. 48).

Este senso comum é marcado pelo discurso da democracia presente na Escola Nova, entretanto, Saviani (2008, p. 51) nos mostra que a pedagogia da essência (tradicional) é revolucionária ao defender a igualdade essencial entre os homens e, consequentemente, o acesso aos conhecimentos.

Nesse sentido, a importância da transmissão de conhecimentos, de conteúdos culturais, marca distintiva da pedagogia da essência, não perde seu caráter revolucionário. A pressão em direção à igualdade real implica a igualdade de acesso ao saber, portanto, a distribuição igualitária dos conhecimentos disponíveis. Mas aqui também é preciso levar em conta que os conteúdos culturais são históricos e seu caráter revolucionário está intimamente associado à sua historicidade. Assim, a transformação da igualdade formal em igualdade real está associada à transformação dos conteúdos formais, fixos e abstratos, em conteúdos reais, dinâmicos e concretos. Ao conjunto de pressões decorrentes do acesso das camadas trabalhadoras à escola, a burguesia responde denunciando pela Escola Nova o caráter mecânico, artificial, desatualizado dos conteúdos próprios da escola tradicional [...] Com isso, a importância da transmissão de conhecimentos foi secundarizada e subordinada a uma pedagogia das diferenças, centrada nos métodos e processos: a pedagogia da existência ou a pedagogia nova (SAVIANI, 2008, p. 51- 52).

Portanto, Saviani nos mostra que a Escola Nova atende aos interesses burgueses, colaborando para a manutenção da ordem burguesa, o que é conseguido por meio da restrição do acesso da classe trabalhadora aos conhecimentos historicamente construídos, deste modo, a educação tradicional é atacada, como percebemos no Relatório Jacques Delors, em detrimento à valorização do indivíduo, dos meios e, desta forma, os conteúdos vão perdendo espaço nas escolas públicas.

Tudo isto nos mostra o caráter antidemocrático presente no Escolanovismo, denunciado por Saviani (2008) visto que, a escola se abriu para a classe trabalhadora 
porém, não lhe garantiu o sucesso escolar, como mostram os dados e inúmeros artigos e produções acadêmicas que tratam da baixa qualidade da educação escolar pública no Brasil. "A Escola Nova contribuiu para o afrouxamento da disciplina e pela secundarização da transmissão dos conhecimentos, para desorganizar o ensino nas referidas escolas" (SAVIANI, 2008, p. 54).

Por tudo isto é que acreditamos ser urgente e necessária a revalorização dos conteúdos escolares em todos os níveis educacionais, sobremaneira, no Ensino Fundamental, etapa obrigatória da escolaridade brasileira. Para tanto, Saviani (2008, p. 5657) propõe uma educação crítica, que seja adequada aos interesses dos trabalhadores, e que parte da prática social (comum a professor e alunos, mas em diferentes níveis de compreensão), no segundo momento, são identificados os problemas apresentados pela prática social (problematização), o terceiro momento, chamado de instrumentalização, é aquele em que os alunos se apropriam dos conhecimentos teóricos e práticos, obtidos pela transmissão direta ou indireta do professor.

Obviamente, não cabe entender a referida instrumentalização em sentido tecnicista. Trata-se da apropriação pelas camadas populares das ferramentas culturais necessárias à luta social que travam diuturnamente para se libertar das condições de exploração em que vivem (SAVIANI, 2008, p. 57).

O quarto passo é chamado de catarse, neste momento, é expressa uma nova forma elaborada de compreensão da prática social, é quando ocorre a efetiva incorporação dos elementos culturais, que agora se transformaram em elementos ativos da transformação social. O quinto e último passo é a própria prática social, não mais compreendida de modo sincrético (simples e desordenado) mas, de modo sintético (em que há uma real compreensão da realidade) (SAVIANI, 2008, p. 57-60) . Estes passos, propostos e debatidos por Saviani desde o início da década de 1980 compõem a chamada Pedagogia Histórico-Crítica.

Esta breve exposição dos passos desta pedagogia justificam nossa defesa dela enquanto alternativa para a revalorização dos conteúdos, dado que, a aquisição deles é etapa importante para a compreensão sintética da prática social, é importante destacarmos aqui duas coisas, a primeira delas é a importância do professor neste processo e a segunda é que não se trata do recebimento mecânico de conteúdos, mas da apropriação deles, de modo que se tornem ferramentas para a transformação social.

Ao tratar dos fundamentos psicológicos da Pedagogia Histórico-Crítica Lígia Márcia Martins (2013, p. 135) atenta que, do ponto de vista psicológico, a construção do conhecimento exige o desenvolvimento do pensamento e condições que os provoquem e os requeiram, e o que oferece estas condições são os conhecimentos clássicos.

Essa proposição demanda compreender que, ao postular os conhecimentos sistematizados como objeto do ensino escolar, a pedagogia histórico-crítica está defendendo a escola como espaço de promoção de desenvolvimento das capacidades humanas complexas, das operações lógicas de raciocínio, dos sentimentos éticos e estéticos, o autodomínio da conduta. Em suma, está defendendo o direito de que todos os indivíduos desenvolvam as funções psíquicas superiores expressas nos comportamentos complexos que a humanidade já consolidou (MARTINS, 2013, p. 315). 
Portanto, a Pedagogia Histórico-Crítica não defende a perpetuação da escola pobre (em conteúdos e recursos) para os pobres, mas, uma escola que ofereça elementos para que todos tenham acesso aos saberes e desenvolvam as funções psíquicas superiores, e estes elementos são os conhecimentos clássicos/científicos.

Saviani conceitua o conhecimento clássico da seguinte maneira:

O clássico não se confunde com o tradicional e também não se opõe, necessariamente, ao moderno e muito menos ao atual. O clássico é aquilo que se firmou como fundamental, como essencial. Pode, pois, constituirse num critério útil para a seleção dos conteúdos do trabalho pedagógico (SAVIANI, 2013, p. 13).

Assim, (SAVIANI, 2013, p. 8-9) nos esclarece que a tarefa da Pedagogia HistóricoCrítica em relação à educação escolar implica a identificação das formas mais desenvolvidas do saber objetivo produzido historicamente pela humanidade; suas condições de produção e manifestação; a conversão do saber objetivo em saber escolar e, o oferecimento de meios para que os alunos apreendam os conhecimentos, suas formas de produção e manifestação.

Portanto, a Pedagogia Histórico-Crítica não descarta a importância dos meios de obtenção dos conhecimentos, porém, enquanto parte do processo de aprendizagem e não como seu próprio fim como propõem as pedagogias do "aprender a aprender". Neste sentido, Lígia Márcia Martins (2011, p. 135 - 136) atenta que, para que ocorra o desenvolvimento é preciso que haja um planejamento intencional das atividades didáticas e que elas permitam a apreensão dos conhecimentos historicamente construídos, nesta perspectiva, os conteúdos constituem o núcleo da educação escolar.

Já a caminho de conclusões, estes breves escritos nos mostram que a educação mundial tem sido afetada pelo "aprender a aprender" que se faz presente na educação brasileira, sobretudo, pela influência da Escola Nova, em consequência disto o que temos visto é a exaltação das individualidades e dos meios de obtenção de conhecimentos, consequentemente temos o esvaziamento curricular em todos os níveis educacionais, inclusive no Ensino Fundamental, cujos objetivos contidos nos PCNs, sequer mencionam os conteúdos.

As competências, capacidades e habilidades aparecem em vários documentos, nos planejamentos escolares e currículos, e afastam nossos alunos dos conhecimentos clássicos científicos, poderíamos aceitar esta situação, como dissemos inicialmente, procurando culpados pelo fracasso da educação pública no Brasil, porém, sabemos que há como mudar este quadro, revalorizando os conteúdos escolares e a própria escola ao forçarmos um movimento na direção oposta ao que tem sido imposto pela normatização educacional.

Acreditamos ser a Pedagogia Histórico-Crítica uma alternativa viável (visto seu sólido embasamento teórico no materialismo histórico dialético e na psicologia históricocultural) para este movimento, uma vez que, está centrada na obtenção dos conhecimentos historicamente construídos, cujo lócus é a escola.

Portanto, nos parece possível a superação do "aprender a aprender", porém, esta tarefa exigirá de nós educadores, empenho no domínio da Pedagogia Histórico-Crítica e persistência no enfrentamento ao senso comum que tomou conta de nossos discursos educacionais. 


\section{Referências}

BRASIL. Casa Civil. Lei 11.274 de 06 de fevereiro de 2006. Disponível em: < http://www.planalto.gov.br/ccivil_03/_Ato2004-2006/2006/Lei/L11274.htm> Acesso em: 21 jan. 2015.

BRASIL. Ministério da Educação e Cultura. Lei de diretrizes e bases da educação nacional. Brasília, $1996 . \quad$ Disponível em: <http://portal.mec.gov.br/seed/arquivos/pdf/tvescola/leis/lein9394.pdf> Acesso em: 05 maio 2012.

BRASIL. Secretaria de Educação Fundamental. Parâmetros curriculares nacionais: introdução aos parâmetros curriculares nacionais. Brasília: MEC/SEF, 1997. 126 p. Disponível em: < http://portal.mec.gov.br/seb/arquivos/pdf/livro01.pdf> Acesso em 21 jan. 2015.

DELORS, Jacques (Org). Educação: um tesouro a descobrir. São Paulo: Cortez/Brasília: MEC: UNESC, $1998 . \quad$ Disponível em: <http://ftp.infoeuropa.eurocid.pt/database/000046001-000047000/000046258.pdf> Acesso em 21 jan. 2015.

DUARTE, Newton. As pedagogias do "aprender a aprender" e algumas ilusões da assim chamada sociedade do conhecimento. Revista Brasileira de Educação. n. 18. Rio de Janeiro, set./ dez. 2001. pp. 35-40. Disponível em: <http://www.scielo.br/pdf/rbedu/n18/n18a04.pdf> Acesso em 21 jan. 2015.

MARTINS, Lígia Márcia. Os fundamentos psicológicos da Pedagogia Histórico- Crítica e os fundamentos pedagógicos da Psicologia Histórico- Cultural. Germinal: Marxismo e Educação em Debate, Salvador, v. 5, n. 2, pp. 130- 143, dez. 2013. Disponível em: <http://www.portalseer.ufba.br/index.php/revistagerminal/article/view/9705> Acesso em 01 out. 2014.

SAVIANI, Dermeval. Escola e Democracia. Campinas, SP: Autores Associados, 2008. 112p. (Coleção educação contemporânea) "Edição Comemorativa".

SAVIANI, Dermeval. Pedagogia Histórico-crítica: primeiras aproximações. $11 \mathrm{ed}$. Campinas, SP: Autores Associados, 2013. 137p. (Coleção Educação Contemporânea).

Recebido: junho-15 Aprovado: agosto-15 